\title{
UM ENSAIO ACERCA DA IMIGRAÇÃO JUDAICA NO BRASIL APÓS O CATACLISMA DE 1933 E DA SEGUNDA GUERRA MUNDIAL (*).
}

\section{FRITZ PINKUSS}

do Departamento de Linguística e Línguas Orientais da Faculdade de Filosofia, Letras e Ciências Humanas da Universidade de São Paulo. Rabino-mor em São Paulo.

No meio da vida cotidiana, com as suas perturbações e com os consequentes movimentos migratórios, geralmente não houve, na história iudaica, a quietude para se escrever relatos históricos. Por isso, os primórdios dos settlements judaicos na diáspora não são bastante claros, sob o ponto de vista do historiador. Por exemplo: Os American Jewish Archives, em Cincinnati, foram fundados neste século para, posteriormente, colecionar material autêntico acerca da imigração dos judeus nos Estados Unidos.

No Brasil aconteceu a mesma coisa, e em vista das tempestades que se abateram sobre o Judaismo desde 1933, e das suas consequências, falta uma coleção de documentos históricos que possa apresentar o quadro da estrutura desta imigração. $O$ autor, contemporâneo dos acontecimentos, tenta com este ensaio assegurar para a historiografia, dados da sua experiência vivida no Brasil. Está no prelo um trabalho sobre a história da Congregação Israelita Paulista, da autoria de Eva, Irene e Gabriela Hirschberg, entidade fundada em 1936, de preferência por judeus de língua alemã, e da qual o autor é co-fundador e rabino-mór. O conteudo daquela monografia não deve ser idêntico ao deste ensaio que resume dados de todo o movimento migratório, desde 1933, para o Brasil.

Com aquela data de 1933 iniciou-se a catástrofe do Judaismo europeu, chegando durante a Segunda Guerra Mundial ao seu climax,

(*). - Este texto foi utilizado pelo Autor numa Conferência pronunciada na Universidade de Hebraica de Jerusalem, em outubro de 1974. (Nota da Redação). 
com o extermínio em massa de seis milhões e meio de seres judaicos. Desde os dias da diáspora, iniciada com a destruição do segundo Estado Judaico em 70 da nossa era pelos romanos, o Judaismo tem sido um fenômeno europeu, até a catástrofe deste século; tambem a grande coletividade judaica dos Estados Unidos, teve origem e feições predominantemente européias. O Judaismo tinha, no decorrer de 19 séculos, os seus centros na Península Ibérica e em todos os paises do Mediterrâneo - judeus sefaradim - e da Europa Central e Oriental - judeus ashquenazim - que estavam em movimentos emigratórios seculares. Houve duas épocas áureas: a dos Sefaradim até a sua expulsão da Península Ibérica (1492), e, mais tarde, nos tempos modernos, depois da Revolução Francesa, apesar de todos os pontos trágicos durante a luta pela Emancipação, na Europa Central e no Leste Europeu.

A partir de 1933 começou a brusca mudança, com o desaparecimento das comunidades européias (exceto na Inglaterra, Suiça e Portugal). Aquilo que tinha sido, durante quase dois milênios, fenômeno europeu, mudou em um decênio, para se tornar fenômeno do hemisfério ocidental e israelense.

Entre os povos americanos, o Brasil recebeu uma imigração relativamente pequena; enquanto houvesse aqui, - conforme os American Jewish Yearbooks - em 1933, cerca de 50.000 almas judaicas, o número hoje é de mais ou menos 160.000 , com coletividades de 65.000 em São Paulo, 50.000 no Rio de Janeiro, 10.000 no Rio Grande do Sul, e o resto distribuido por todo o território nacional.

A política imigratória do Brasil foi inicialmente liberal; com o advento do Estado Novo ficou dificultada até paulatina e ser praticamente suspensa (1), $\mathrm{O}$ autor supõe que o Presidente Getúlio Vargas fazia bastante esforços para não entrar em choque com os sistemas totalitários, os quais tinham influência no seu estilo de pensar e de agir. A partir dos governos dos Presidentes Dutra e Kubitchek, esta política imigratória foi outra vez liberalizada, especialmente pelo segundo.

Por que motivos foi o Brasil uma meta muito procurada para os que tinham de se refugiar? A resposta é óbvia para quem tem uma experiência com os fenômenos históricos de migração judaica: onde houve depois de crises um novo começo, os judeus sentiram o desafio de se intercalarem naqueles territórios e nações, com suas aptidões específicas, no sentido de reconstrução e evolução das economias e da vida cultural após as crises. Em 1929 houve a recessão mundial, nos anos de 20 e de 30 deste século XX; houve as diversas revoluções

(1). - Ela continuava em certas épocas facilitada somente para agricultores. O então existente Conselho de Imigração não foi favoravel à imigração citadina (veja os relatos das suas reuniões). 
internas no País, - especialmente a Constitucionalista de 1932 - e não restava dúvida que a reconstrução de um país jovem, com as suas imensas possibilidades econômicas e culturais, oferecia um convite aos olhos de gente européia bem educada e bem preparada, que estava a procura de novas chances para a vida.

\section{Etapas da Imigração.}

Logo em 1933 chegaram os jovens, na grande maioria dos casos não tendo ainda constituido família. Eles tinham seus diplomas e seu preparo profissional, tendo começado carreiras bruscamente interrompidas pelas leis anti-semitas alemãs. Foi para eles necessário um tremendo esforço para se adaptar a circunstâncias de novas vidas, naquela época bastante diferentes das da Europa, especialmente para aqueles que pertenciam às profissões liberais, cujos diplomas não foram reconhecidos. Com relativamente bem poucas tragédias individuais, eles conseguiram radicar-se e tornaram-se precursores (Schrittmacher) da $2^{\mathrm{a}}$ etapa imigratória, a das famílias das quais originaram e que tinham logo tambem de se decidir pela saida da Europa Central.

A segunda fase é a que se extende de 1936-1937 até a 2â Guerra Mundial. A migração judaica, como se sabe através do exemplo da imigração nos EEUU, foi sempre a de famílias. Os jovens, ainda não casados, mandaram vir seus familiares: pais, irmãos, noivas e noivos. Com a tremenda deterioração em 1937-1939 da situação na Europa, e com a horrivel intensificação e acumulação de leis e atos anti-semitas, com a anexação da Austria, tratado da Checoslováquia, destruição das sinagogas, abertura de cada vez mais campos de concentração e consequente insegurança até física dos judeus, com o perigo de guerra iminente, tambem as famílias radicadas resolveram emigrar, deixando atrás de si todos os seus bens móveis e imóveis, todas as suas relações humanas que geralmente existiam na Europa, entre judeus e seus amigos gentios.

Uma observação esclarecedora: o autor, primeiro rabino europeu que emigrou, depois de ter ajudado na Europa, em Heidelberg, a centenas e centenas de jovens, judeus e cristãos indistintamente, que estavam expostos aos perigos, - sempre fora receioso de que com a guerra iminente, estas vítimas iam ser levadas às minas de carvão, etc. para trabalhos forçados - jamais foi-lhe possivel imaginar a fúria dos campos de concentração e das câmaras de extermínio.

Os judeus do Leste europeu estavam em situação muito mais trágica ainda; enquanto os centro-europeus tinham em todo o caso uma chance e um prazo para se preparar - meșmo a curto termo para a emigração; aqueles do Leste europeu, as grandes massas, de 
um dia para outro estavam indefesas, entregues às mãos dos seus carrascos. Houve casos isolados em que foi possivel a amigos cristãos prestar ajuda que infelizmente se tornou somente temporária, e houve provas nos levantes dos ghettos - especialmente no de Varsóvia, de que as vítimas preferiram defender-se, cientes que a luta era desigual e sem perspectivas de sobrevivência.

Por que a preferência das famílias para o Brasil? Temos várias respostas: a). - os filhos solteiros já estavam no país; b). - os esparsos meios financeiros que porventura estas conseguiram salvar, - geralmente o Marco bloqueado valia $10 \%$ ou menos ainda, no mercado de capitais, representou em Mil-Réis ainda um pequeno pecúlio inicial [pode avaliar-se que em média chegaram com cerca de cem Contos de Réis, na categoria de "capitalistas", ou por carta de chamada mandada pelos filhos]. Isto se refere essencialmente aos judeus centro-europeus; c). - de grande valor, que jamais deve ser sub-estimado, foi o carater humanitário das autoridades e, muito mais ainda, do próprio povo que ofereceu um amparo moral aos que estavam à procura de uma nova razão de existir.

Com os escassos recursos (que baixaram enfim até somente dez marcos alemães) estes imigrados intercalaram-se na economia brasileira, como representantes, corretores, assim como na agricultura, na qual tiveram que se adaptar. Um fator muito apreciado foi a possibilidade, especialmente nas Capitais, de fundar pequenas indústrias, típicas na economia de São Paulo, as quais, com o esforço de guerra do país, transformaram-se em firmas respeitáveis. Esta onda terminou, como já foi dito, praticamente com os primeiros anos do Estado Novo. Os que trouxeram alguns meios mais amplos, de preferência entraram no comércio de exportação ou de importação, ou em negócios de construção.

Ainda a partir de 1939 , vieram - via Itália, mais tarde via o Japão, enquanto estes não estavam em guerra, e via África do Norte e Portugal, - outros grupos: os avós dos imigrados da primeira camada de 1933. Com o início da guerra, a todos estes imigrados ficou dificultada a vinda pelas leis restritivas acerca dos "súditos do eixo" e da proibição do uso das suas línguas. O autor lembra-se das inúmeras vezes que teve de dar garantia às autoridades em favor desta gente velha, descoberta e presa por falar uma "língua do eixo".

Simultaneamente chegara no início da guerra a imigração da Itália fascista. Enquanto o povo italiano. - como aliás tambem os pequenos povos da Europa, especialmente Holanda, Bélgica, Escandinávia - se destacaram pelas suas atitudes fraternais e humanitárias, o governo italiano tinha de obedecer, na sua política anti-judaica, 
aos alemães. E notavel observar, como o autor tivera em 1933 uma entrevista secreta em Londres com uma pessoa de destacado lugar na hierarquia italiana, a qual lhe respondeu que já naquela época Mussolini era virtualmente prisioneiro dos alemães e não podia fazer nada em favor dos judeus.

Depois da "Anexação da Áustria" veio uma onda de judeus daquele País e dos territórios da antiga monarquia do Danúbio, cuja integração processou-se de forma idêntica à dos centro-europeus.

A grande tragédia foi a dos remanescentes da guerra (Displaced-Persons), restos das grandes comunidades do Leste europeu. E é um fato honroso como o então Governo do Brasil, e as organizações judaicas internacionais e locais, deram àquelas vítimas um apôio fraternal e generoso, aquele concendendo vistos e estas ajudando indivíduos da comunidade judaica "deslocados" a radicaram-se.

Com a situação piorando no Oriente Médio, chegaram as ondas imigratórias dos paises árabes, material humano especialmente inteligente e preparado. Em menor escala, chegaram mais tarde, em consequência das crises naquela região, no último decênio: os Yordim, emigrados de Israel, - aqueles que não tinham tido êxito em adaptar-se ao País oriental que é Israel, e que em parte aí ficaram, e que em parte posteriormente reemigraram para Israel ou para os seus paises de origem.

Uma imigração em pequena escala chegou nos últimos anos, vinda de paises sul-americanos em crise, atraidos pelo boom econômico brasileiro depois da revolução de 1964 .

\section{Características da Imigração.}

Devemos acrescentar àquilo que já foi dito anteriormente: a integração não ofereceu em geral dificuldades básicas em vista da ausência de anti-semitismo, - e graças ao espírito fraternal do povo, o número de suicídios foi muito menor do que em outros centros de imigração. A política imigratória do Estado Novo não parecia claramente definida, - ela era ambi-valente, e em consequência houve muitos casos em que os refugiados que não podiam absolutamente ficar nos paises de origem, tentaram chegar, por força das circunstâncias, a título de turistas, com a esperança de poder logo legalizar a sua situação. Isto às vezes deu certo, porem muitos foram presos e deportados, ou proibidos de desembarcar. Paises como o Uruguai, a Argentina e a Bolívia os aceitaram após muitas negociações, de sorte 
que praticamente só em raros casos, - aliás extremamente trágicos - foram os infelizes mandados de volta para encontrar um destino dos mais tristes. Vários transmigrantes dos paises da Prata, voltaram ao Brasil, com a sua situação legalizada. Como já dissemos, Vargas tinha receio dos alemães - assim parece - e suspendeu a imigração para lhes agradar; dias antes da entrada do Brasil na guerra, fez, em um discurso, violentas observações acerca dos "sem pátria", mas parece que o encontro dele com Roosevelt em Natal, em 1942, desanuviou a situação, com a consequente entrada do Brasil na guerra ao lado dos Aliados.

Da parte do Vaticano houve intervenção do Papa Pio XII a favor de descendentes de judeus, qualificados pelas leis "arianas" ainda como "judeus". Houve uma quota de imigração para "judeus católicos". Falam em honra do nosso povo brasileiro aqueles que foram admitidos, sob esta quota, - judeus que se tinham batizado ad hoc. Assim se criou uma nova espécie de "cristãos-novos". Ao autor, jovem rabino em São Paulo, chegavam muitos telegramas naqueles dias críticos de 1938-39, pedindo orientação em vista do perigo de ficar e morrer, ou salvar-se através do batismo. Durante séculos nenhum rabino tivera de enfrentar sozinho, e resolver, o problema dos cristãos-novos. Estes, não em número relevante, chegaram. Alguns, como preito de gratidão ou por medo, ficaram, chegados ao Brasil, como marranos; a grande maioria retornou ao judaismo, sem esquecer a sua gratidão aos sacerdotes cristãos. Os que tinham prestado ajuda foram geralmente padres em posições não muito altas na hierarquia, mas houve tambem até cardeiais, como o saudoso Cardeal Schuster, Arcebispo de Milão - que tinha dado ordem ao seu clero para prestar toda a forma de socorro. Já foi dito que os presidentes Dutra e especialmente Kubitschek, introduziram uma política humanitária de imigração em salvação para muitos dos displaced persons (2).

\section{A adaptação profissional.}

Ela foi facilitada enormemente pela participação no esforço de guerra. População citadina, radicou-se em todas as profissões: como industriais, corretores, importadores e exportadores. Mas há de observar-se o seguinte: médicos e advogados, salvo casos em que reco-

(2). - Lembra-se o autor que, quando houve - não no Brail - mas no exterior, os primeiros atos violentos de terror, Kubitschek apareceu uma manhã no Lar dos Velhos Israelitas no Rio de Janeiro onde beijou algumas velhas - que nem sabiam de quem fora a visita, prometendo-lhes que não aconteceria nenhum ato de terror a elas no Brasil. 
meçaram os estudos para aqui se diplomarem, tiveram que contentar-se com ocupações próximas, os médicos, por exemplo como laboratoristas, os advogados como conselheiros, etc., sendo que a maioria deles mudou totalmente de profissão.

Há uma tendência natural do imigrado unir-se a seus grupos étnicos; assim, houve uma certa aglomeração nas cidades, onde prestaram relevantes serviços, especialmente no interesse da industrialização estimulada durante a guerra e mais ainda desde a revolução de 1964. Tambem temos que mencionar duas tentativas bem sucedidas de distribuição de imigrantes por todo o Pais, e especialmente na agricultura. Houve empreendimentos organizados para radicar famílias nas pequenas cidades, de preferência no Sul. E no Norte do Paraná, especialmente através dos trabalhos da Paraná Plantations, fundaram-se fazendas, geralmente de tamanho pequeno e médio, onde estes imigrados se radicaram muito bem e se tornaram ativos na produção de café, algodão, ramí, soja, feijão, gado, etc. .

Durante a guerra, os imigrados sofreram com a ambiguidade da sua situação legal: eram "inimigos do eixo", mas juridicamente "súditos do eixo". Sofreram pequenas e maiores dificuldades como súditos do eixo, comn a proibição do uso do idioma materno, - o que afetou os velhos - , as dificuldades de serem obrigados a pedir salvo-condutos para viajar, e os "confiscos de bens" e restrições impostas aos "súditos do eixo" conforme o decreto-lei 4.166. Não resta dúvida alguma que estavam ao lado do Brasil, oferecendo-se como os "aliados esquecidos", os seus filhos, ao esforço de guerra, e dando provas de gratidão a quem os salvara, o que nem sempre foi bem visto pelos grupos conservadores do País. Aqui cabe novamente um depoimento pessoal: em um encontro com um diplomata dos aliados, este referiu-se ao fato de que aqueles que eram amigos declarados do Brasil, ficaram oficialmente desconhecidos como tais. Temos de admitir francamente que foi uma situação dificil do ponto de vista jurídico para os paises: a de formular e praticar definições e distinções adequadas e claras, naquela situação confusa.

\section{Organização e aculturação.}

Em resumo, desde 1933 formaram-se nas Capitais associações de carater social, de ajuda, de cultura, e naturalmente de vida religiosa, nos mesmos moldes daquelas que prevaleciam na Europa. Houve a fundação em São Paulo de S. I. P. (Sociedade Israelita Paulista) que mais tarde passou a denominar-se Congregação Israelita Paulista, entidade fundada em 1936, e cuja história está sendo escrita. No Rio de Janeiro existia a "União" de assistência social e, em 1942, 
fundou-se tambem a ARI (Associação Religiosa Israelita). As duas são hoje as congregações-líderes do Pais que, fundadas por refugiados, transformaram-se em congregações judaicas de carater estritamente brasileiro, com uma iuventude educada no civismo brasileiro. Elas tinham uma função histórica a cumprir: a de criar uma vida religiosa comunal moderna no Brasil. Simultaneamente, criou-se em Porto-Alegre a comunidade "SIBRA" em moldes idênticos. Tambem outras congregações de sefaradim e de ashqenazim fundaram-se nas Capitais, pelos imigrados desejosos de manter e viver a sua identidade religiosa, herdada das gerações que lhes tinham precedido nos paises de origem. A quase todas as cidades chegaram famílias judaicas destas ondas imigratórias, integrando-se nas comunidades menores, nas associações e "Centros" já existentes ou a serem por eles co-fundadas.

A aiuda prestada seguiu as linhas comprovadas e praticadas em dois milênios no meio judaico (3). Com o ano 1933 fundaram-se em todas as partes do Pais comitês, muitas vezes por iniciativas emanadas e praticadas pelas Fraternidades BNE BRIT, onde se davam conselhos, animação, ajuda cultural-educativa, enfim, toda espécie de assistência social, e onde os recem-vindos encontraram irmãs, e irmãos judeus e muitas vezes tambem cristãos, que lhes ofereceram a primeira base de vida: colocações. Este trabalho ficou incorporado nas Capitais em organizações comunitárias, como a "CIP" (Congregação Israelita Paulista) ou a "ARI" e a "UNIÃO", em geral com incumbências tão múltiplas que iam alem das possibilidades locais. Jamais faltou a generosa ajuda dos grandes organismos internacionais, como a "ICA" (Jewish Colonisation Association), a "HIAS" e mais do que todos, do American Joint Jewish Distribution Committee. A história judaica foi comparada à roda de um carro: algumas vezes uma parte da roda está em baixo e depois esta mesma volta a estar em cima. Assim, os que receberam amparo humano, após o decorrer dos anos, conseguiram, em gratidão, prestar amparo por sua vez aos necessitados.

As grandes congregações e organizações promoveram a aculturação sem ter, praticamente, nenhuma dificuldade. Elas servem em todos os ramos da vida religiosa, educativa, cívica, cultural, baseiando-se em exemplos europeus e americanos da vida judaica, mas ansiosas e bem sucedidas em criar um estilo autenticamente brasileiro: - especialmente através de planejamentos de instrução e educação e de informática que criam o tipo do judaismo brasileiro intelectual de hoje. Assim sendo, o contato dos "refugiados" com os paises de origem é reduzi-

(3). - O trabalho de todas as instituições de assistência nunca ficou restrito aos recem-imigrados, nem aos próprios judeus. 
do, principalmente em consequência das experiências vividas pelas famílias e pelos sacrifícios humanos sofridos.

A nova geração é brasileira consciente, graças ao convívio que oferece o Brasil a todos os credos e raças e à sua força assimiladora. Aqui no Brasil foi bem sucedido o esforço de criar com o bom material humano que compõem as instituições-líderes judaicas e com a sua liderança esclarecida, educar uma nova geração, na síntese operante do civismo com um judaismo baseado livremente na tradição com os seus valores humanos e humanitários.

Antigos "refugiados" tomam parte ativa nas iniciativas dos organismos locais, estaduais e de âmbito nacional do judaismo brasileiro, em assuntos comunitários, representativos, culturais, religiosos e administrativos.

\section{BIBLIOGRAFIA.}

Os American Jewish Yearbooks desde 1933, editados pelo American Jewish Committee, New York.

rrnnica Israelita, Resenha Judaica de São Paulo, boletins da "ARI" e "UNIÃO" do Rio de Janeiro.

História da Congregação Israelita Paulista (Eva Hirschberg e filhas) no prelo. As publicações do autor, especialmente Israel Povo dos Milênios.

Muitos dados baseiam-se nas experiências do autor feitas em quase quatro decênios de funções rabínicas em São Paulo.

FRITZ PINKUSS. Nascido a 13 de maio de 1905 na cidade de Egeln, no distrito de Magdeburgo (Alemanha). Cidadão brasileiro por natu:alização. Licenciado em Filosofia, Pedagogia, Filologia Semítica (1925-1929) pelas Universidades de Breslau e Würburg. Doutor em Filosofia. De 1930 a 1936 - Rabino do distrito de cidade de $\mathbf{H}$.idelberg. A partir de 1936, fundador, rabino, pregador, diretor do ensino religioso da Congregação Israelita Paulista.

A partir de 1945 professor do Curso de Língua e Literatura Hebraica da Faculdade de Filosofia, Letras e Ciências Humanas da Universidade de São Paulo. 